\title{
Factor Analysis of Changes in Hemoglobin A1c After 12 Months of Sitagliptin Therapy in Patients With Type 2 Diabetes
}

\author{
Shouhei Yuasa ${ }^{a}$, Kazuyoshi Sato ${ }^{a}$, Masahiko Takai ${ }^{b}$, Masashi Ishikawa ${ }^{b}$, Shinichi Umezawa ${ }^{\mathrm{b}}$, Akira Kubota $^{\mathrm{b}}$, \\ Hajime Maeda $^{\mathrm{b}}$, Akira Kanamori ${ }^{\mathrm{b}}$, Masaaki Miyakawa ${ }^{\mathrm{a}}$, Yasushi Tanaka ${ }^{\mathrm{c}}$, Yasuo Terauchid ${ }^{\mathrm{d}}$, \\ Ikuro Matsuba ${ }^{b, e}$
}

\begin{abstract}
Background: Sitagliptin, a dipeptidyl peptidase- 4 inhibitor, is an effective oral antidiabetic agent as both monotherapy and when combined with insulin. Data from three observational studies performed in patients with type 2 diabetes receiving sitagliptin therapy in the routine clinical setting were integrated to conduct factor analysis of the changes in hemoglobin A1c (HbA1c), body weight, and estimated glomerular filtration rate (eGFR) over 12 months.

Methods: Among patients with type 2 diabetes attending medical institutions affiliated with Kanagawa Physicians Association, those using sitagliptin were followed for 1 year. In the ASSET-K and ASSIST$\mathrm{K}$ studies, patients were managed by diabetologists, while they were managed by non-diabetologists in the ATTEST-K study. Patients were not administered insulin in ASSET-K, whereas insulin was administered in ASSIST-K. HbA1c (National Glycohemoglobin Standardization Program), blood glucose (fasting/postprandial), body weight, and renal function (serum creatinine and eGFR) were the efficacy endpoints. Factor analysis was performed by analysis of variance using the magnitude of the change in HbAlc, body weight, and eGFR after 12 months of sitagliptin therapy as response variables, and the study, sex, and age as explanatory variables.
\end{abstract}

Results: Of 1,327 patients registered in ASSET-K (diabetologists/ without insulin), 1,167 patients in ASSIST-K (diabetologists/with insulin), and 530 patients in ATTEST-K (non-diabetologists), statistical analysis was carried out on 1,074, 854, and 411 patients, respectively.

Manuscript accepted for publication March 22, 2016

aStudy Group of the Hypertension Committee, Kanagawa Physicians Association, Kanagawa, Japan

bStudy Group of the Diabetes Committee, Kanagawa Physicians Association, Kanagawa, Japan

'Division of Metabolism and Endocrinology, Department of Internal Medicine, St. Marianna University School of Medicine, Kanagawa, Japan

${ }^{\mathrm{d}}$ Department of Endocrinology and Diabetes, Yokohama City University Medical Center, Kanagawa, Japan

${ }^{e}$ Corresponding Author: Ikuro Matsuba, Matsuba Medical Clinic, 2-159 Tsukagoshi, Saiwai-ku, Kawasaki-shi, Kanagawa 212-0024, Japan.

Email: ikuro@matsuba-web.com

doi: http://dx.doi.org/10.14740/jocmr2540w
There were significant inter-study differences in patient characteristics (complications, duration of diabetes, and baseline $\mathrm{HbAlc}$ ), the sitagliptin dose, and the use of other antidiabetic agents. HbAlc decreased significantly in all three studies. According to factor analysis, the magnitude of the change in HbA1c over 12 months showed significant inter-study differences and was also significantly influenced by the age, duration of diabetes, and baseline HbAlc.

Conclusions: Comparison of three observational studies identified differences in patient characteristics, treatment of diabetes (use/ non-use of insulin), and the level of specialist care (diabetologist/ non-diabetologist). Despite such differences, consistent reduction of HbA1c by sitagliptin was demonstrated in all three studies. The patients showing most improvement in $\mathrm{HbA} 1 \mathrm{c}$ with sitagliptin therapy were older patients with a short duration of diabetes and high baseline HbA1c level.

Keywords: Type 2 diabetes; DPP-4 inhibitor; Sitagliptin; Hemoglobin A1c; Body weight; Estimated glomerular filtration rate

\section{Introduction}

Dipeptidyl peptidase-4 (DPP-4) inhibitors are a new class of oral hypoglycemic agents that selectively inhibit DPP-4, an enzyme that breaks down incretins (glucagon-like peptide-1 and glucose-dependent insulinotropic polypeptide), thus increasing endogenous incretin levels and promoting insulin secretion in a glucose-dependent manner [1]. In 2015, a total of eight DPP-4 inhibitors are available in Japan. Meta-analyses have not shown any significant differences in the hypoglycemic action of various DPP-4 inhibitors [2, 3], and these drugs are characterized by a good safety profile with a low risk of causing hypoglycemia or weight gain [4].

Sitagliptin was the first DPP-4 inhibitor developed in Japan, and it was launched in 2009 [5]. Its efficacy has been confirmed when used either as monotherapy or in combination with oral agents or insulin [6]. We previously investigated the efficacy and safety of sitagliptin based on the 12-month outcome in patients with type 2 diabetes mellitus (T2DM), excluding those receiving insulin, who had poor glycemic control and were managed by diabetologists in the routine clinical 
Table 1. Patient Characteristics

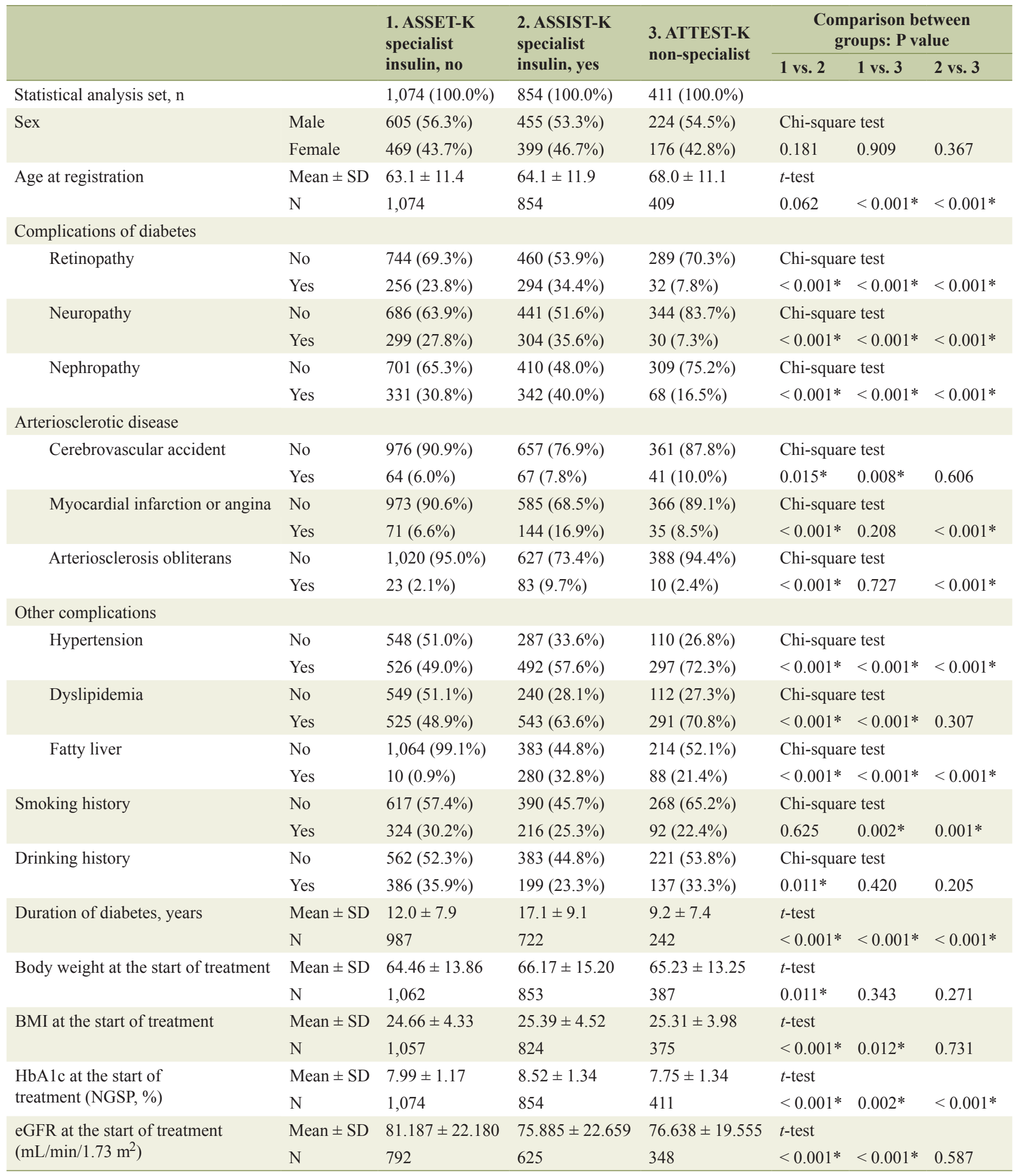

${ }^{*} \mathrm{P}<$ 0.05. SD: standard deviation; BMI: body mass index; HbA1c: hemoglobin A1c; NGSP: National Glycohemoglobin Standardization Program; eGFR: estimated glomerular filtration rate. 
setting (ASSET-K study), revealing that sitagliptin reduced hemoglobin A1c (HbA1c) [7] and also reduced the blood pressure and serum lipid levels [8]. In addition, factor analysis was employed to assess the changes in $\mathrm{HbAlc}$ after starting sitagliptin therapy [9-12], and its impact on serum creatinine [13]. We also conducted a similar study in patients with T2DM receiving insulin (ASSIST-K study), which again demonstrated the HbA1c-lowering action of sitagliptin [14], and performed factor analysis of the changes in HbA1c [15].

The present study (ATTEST-K) was performed to investigate the 12-month course during sitagliptin therapy in T2DM patients with poor glycemic control who were not being treated by diabetologists. In addition, data from the above-mentioned three studies (ASSET-K, ASSIST-K, and ATTEST-K) were integrated to conduct factor analysis of the changes in $\mathrm{HbAlc}$, body weight (BW), and estimated glomerular filtration rate (eGFR) over 12 months.

\section{Patients and Methods}

\section{Study design}

All three studies (ASSET-K, ASSIST-K, and ATTEST-K) were observational studies with a 1-year follow-up period, and were multicenter studies performed at medical institutions affiliated with Kanagawa Physicians Association. All the studies were performed in accordance with the principles set out in the Declaration of Helsinki. ASSET-K and ASSIST-K enrolled patients managed by diabetologists, whereas ATTEST-K was performed in patients who were not managed by diabetologists.

\section{Patients}

The subjects were patients over 20 years old with T2DM who attended the outpatient clinics of medical institutions affiliated with Kanagawa Physicians Association and were treated with sitagliptin. In all patients, glycemic control was inadequate for at least 1 month before the start of sitagliptin administration in spite of diet/exercise therapy or diet/exercise therapy combined with an antidiabetic agent. In the ASSIST-K study, patients were concomitantly treated with insulin.

All of the studies excluded patients with a history of hypersensitivity to any component of sitagliptin, patients with a history of severe ketoacidosis, diabetic coma, or precoma within the previous 6 months, patients with severe infection, patients scheduled to have surgery, patients with severe trauma, patients treated with glinides, and other patients judged to be inappropriate for the study by the attending physician. Patients on insulin therapy were also excluded from the ASSETK study.

\section{Items investigated}

The patient characteristics investigated were sex, age, height, duration of diabetes, family history, smoking, alcohol intake, and complications. Information on medical treatment included the administration of sitagliptin or other antidiabetic agents before sitagliptin therapy, at baseline, and after 1 year of sitagliptin treatment. Efficacy endpoints were HbAlc (National Glycohemoglobin Standardization Program), blood glucose (fasting/postprandial), BW, blood pressure (systolic/diastolic), liver function tests (glutamic oxaloacetic transaminase, glutamic pyruvic transaminase, and $\gamma$-glutamyl transpeptidase), renal function tests (serum creatinine and eGFR), serum lipids (total cholesterol, low-density lipoprotein cholesterol, highdensity lipoprotein cholesterol, and triglycerides), and serum amylase at each time of assessment. Adverse events were also investigated as the safety endpoint.

\section{Statistical analysis}

Among the registered patients, those in whom $\mathrm{HbAlc}$ was measured at baseline and after 1 year of sitagliptin treatment (the population in which the change in HbAlc over 12 months could be calculated) were included in statistical analysis. Appropriate descriptive statistics were compiled for patient characteristics such as sex, age, and the presence/absence of diabetic complications in each study, after which inter-study comparison was performed by using the $t$-test and the Chisquare test. The number of patients receiving antidiabetic agents (insulin, sulfonylureas (SUs), biguanides (BGs), thiazolidinediones (TZDs), $\alpha$-glucosidase inhibitors ( $\alpha$-GIs), and glinides) and the distribution of therapeutic agents were calculated before sitagliptin administration, at baseline, and after 1 year of sitagliptin treatment. Then inter-study comparison was conducted by the Chi-square test and Wilcoxon's test. Descriptive statistics were calculated for the daily dose of sitagliptin at baseline and after 1 year, and inter-study comparison was carried out with Wilcoxon's test.

Measured values of HbAlc, BW, and eGFR at baseline and after 3, 6, and 12 months of treatment, as well as the magnitude of change at each time point were displayed in graphs, and inter-study comparison was performed by using the $t$-test. In addition, factor analysis of the magnitude of changes at 12 months was carried out by analysis of variance using explanatory variables such as the study, sex, and age. After univariate analysis of each explanatory variable, the early multivariate model was constructed by including all explanatory variables showing a significant influence at $\mathrm{P}<0.05$. Backward elimination using $\mathrm{P}<0.05$ as the criterion was applied to the early model to construct the final multivariate model.

\section{Results}

\section{Handling of the subjects}

A total of 1,327 patients were registered in the ASSET-K (diabetologists/without insulin), 1,167 patients in the ASSIST-K study (diabetologists/with insulin), and 530 patients in the ATTEST-K study (non-diabetologists). Among them, statistical analysis was conducted for 1,074 patients from ASSET-K, 
854 patients from ASSIST-K, and 411 patients from ATTEST$\mathrm{K}$ after excluding patients without $\mathrm{HbAlc}$ data at baseline and/ or 12 months.

\section{Demographic factors}

Table 1 shows a summary of patient characteristics and the results of inter-study comparison. With respect to the sex ratio, men were predominant in all studies $(56.3 \%$ in ASSET$\mathrm{K}, 53.3 \%$ in ASSIST-K, and $54.5 \%$ in ATTEST-K). The mean age was the highest in the ATTEST-K study (68.0 years), followed by the ASSIST-K study (64.1 years) and the ASSET-K study (63.1 years) in that order. Among diabetic complications, retinopathy showed the highest prevalence of $34.4 \%$ in the ASSIST-K study, followed by $23.8 \%$ in the ASSETK study and $7.8 \%$ in the ATTEST-K study. The percentage of patients with neuropathy and nephropathy was highest in the ASSIST-K study, followed by ASSET-K and ATTEST$\mathrm{K}$. With respect to arteriosclerotic disease, the percentage of patients with a history of myocardial infarction/angina was highest in the ASSIST-K study (16.9\%), whereas it was under $10 \%$ in ASSET-K and ATTEST-K. The percentage of patients with cerebrovascular disease and arteriosclerosis obliterans was below $10.0 \%$ in all three studies. With respect to other complications, the percentage of patients with hypertension was highest in the ATTEST-K study (72.3\%), followed by ASSIST-K (57.6\%) and ASSET-K (49.0\%). Results for patients with dyslipidemia were similar to those for hypertension. The percentage of patients with fatty liver was highest at $32.8 \%$ in the ASSIST-K study, followed by $21.4 \%$ in ATTEST-K and $0.9 \%$ in ASSET-K. The mean duration of diabetes was the longest at 17.1 years in the ASSIST-K study, followed by 12.0 years in ASSET-K and 9.2 years in ATTEST-K. Mean BW was highest at $66.17 \mathrm{~kg}$ in the ASSIST-K study, followed by $65.23 \mathrm{~kg}$ in ATTEST-K and $64.46 \mathrm{~kg}$ in ASSET-K, with the order of mean body mass index (BMI) being the same as that of BW. Mean baseline HbA1c was highest at $8.52 \%$ in the ASSIST-K study, followed by $7.99 \%$ in ASSET-K and $7.75 \%$ in ATTEST-K. Mean baseline eGFR $\left(\mathrm{mL} / \mathrm{min} / 1.73 \mathrm{~m}^{2}\right)$ was the highest at 81.187 in the ASSET-K study, followed by 76.638 in ATTEST-K and 75.885 in ASSIST-K.

\section{Antidiabetic agents}

Table 2 shows a summary of the inter-study comparison of antidiabetic agents used by the patients. The mean number of antidiabetic drugs used before the start of sitagliptin therapy was 2.0 in the ASSIST-K study, while it was 1.8 in ASSET-K and 1.0 in ATTEST-K. The percentage of patients on insulin therapy was $0.0 \%$ and $100.0 \%$ in the ASSET-K and ASSIST-K studies, respectively, reflecting the eligibility criteria of these studies, while $2.2 \%$ of patients received insulin in the ATTEST-K study. Oral antidiabetic agents administered to more than $30 \%$ of the patients were SUs $(65.3 \%)$ and BGs $(51.0 \%)$ in the ASSET-K study, BGs (41.5\%) in the ASSIST-K study, and SUs (35.5\%) in the ATTEST-K study.

The mean starting dose of sitagliptin was $49.52 \mathrm{mg}$ in the
ASSIST-K study, $46.42 \mathrm{mg}$ in the ASSET-K study, and 49.20 $\mathrm{mg}$ in the ATTEST-K study. Compared with before sitagliptin therapy, the mean number of antidiabetic agents other than sitagliptin decreased to 1.9 during sitagliptin therapy in the ASSIST-K study, followed by 1.5 in ASSET-K and 0.9 in ATTEST-K. Concomitant antidiabetic agents showing a decrease in prescription by $\geq 3 \%$ compared with before sitagliptin therapy were TZDs ( $26.9 \%$ vs. $23.7 \%), \alpha$-GIs $(27.3 \%$ vs. $23.7 \%$ ), and glinides ( $7.9 \%$ vs. $2.2 \%)$ in the ASSET-K study, TZDs $(10.8 \%$ vs. $6.7 \%)$ and $\alpha$-GIs $(26.6 \%$ vs. $20.4 \%)$ in the ASSIST-K study, and TZDs (19.2\% vs. $12.9 \%), \alpha$-GI $(18.7 \%$ vs. $10.0 \%)$ and glinides (5.6\% vs. $0.0 \%)$ in the ATTEST-K study.

In all three studies, the mean dose of sitagliptin was higher after 12 months than at the start of treatment, being 56.98 $\mathrm{mg}$ in ASSIST-K, $52.22 \mathrm{mg}$ in ASSET-K, and $51.91 \mathrm{mg}$ in ATTEST-K. However, the mean number of antidiabetic agents other than sitagliptin showed little change compared with the start of treatment: 1.8 in ASSIST-K, 1.5 in ASSET-K, and 0.9 in ATTEST-K. Of the concomitant antidiabetic agents, those showing changes in administration by $\geq 3 \%$ compared with the start of sitagliptin therapy were BGs (48.5\% vs. 53.8\%) in ASSET-K, BGs (39.6\% vs. $33.4 \%$ ) in ASSIST-K, and SUs $(37.2 \%$ vs. $40.4 \%)$ and BGs $(22.6 \%$ vs. $26.0 \%)$ in ATTEST$\mathrm{K}$.

\section{Changes in HbA1c, BW, and eGFR}

After 12 months, mean $\mathrm{HbAlc}$ decreased from $7.99 \%$ to $7.31 \%$ in the ASSET-K study, from $8.52 \%$ to $7.91 \%$ in ASSIST-K, and from $7.75 \%$ to $6.90 \%$ in ATTEST-K, and the actual change (mean \pm standard deviation (SD)) at 12 months was $-0.68 \pm 1.08 \%,-0.61 \pm 1.20 \%$, and $-0.84 \pm 1.10 \%$, respectively (Fig. 1). HbA1c decreased significantly after 12 months in all three studies.

After 12 months, mean BW changed from 64.46 to 64.75 $\mathrm{kg}$ in the ASSET-K study, from 66.17 to $66.08 \mathrm{~kg}$ in ASSIST$\mathrm{K}$, and from 65.23 to $65.38 \mathrm{~kg}$ in ATTEST-K, and the actual change (mean $\pm \mathrm{SD}$ ) at 12 months was $0.11 \pm 2.94,-0.09 \pm$ 4.26 , and $-0.23 \pm 2.98 \mathrm{~kg}$, respectively (Fig. 2). A significant change in BW was not observed in any of the studies.

After 12 months, mean eGFR $\left(\mathrm{mL} / \mathrm{min} / 1.73 \mathrm{~m}^{2}\right)$ decreased from 81.19 to 76.50 in the ASSET-K study, from 75.88 to 71.65 in ASSIST-K, and from 76.64 to 72.26 in ATTEST-K, and the actual change (mean $\pm \mathrm{SD}$ ) at 12 months was $-3.88 \pm$ $14.94,-4.29 \pm 13.08$, and $-4.03 \pm 10.27$, respectively (Fig. 3). There was a significant decrease in eGFR in all three studies.

\section{Factor analysis of the changes in HbA1c, BW, and eGFR at 12 months}

Table 3 shows the results of factor analysis of the change in HbAlc after 12 months of treatment with sitagliptin. The factors with a significant influence on the change in $\mathrm{HbAlc}$ according to univariate analysis were the study, age at registration, duration of diabetes, baseline $\mathrm{HbA} 1 \mathrm{c}$, and baseline eGFR. 
Table 2. Use of Antidiabetic Drugs

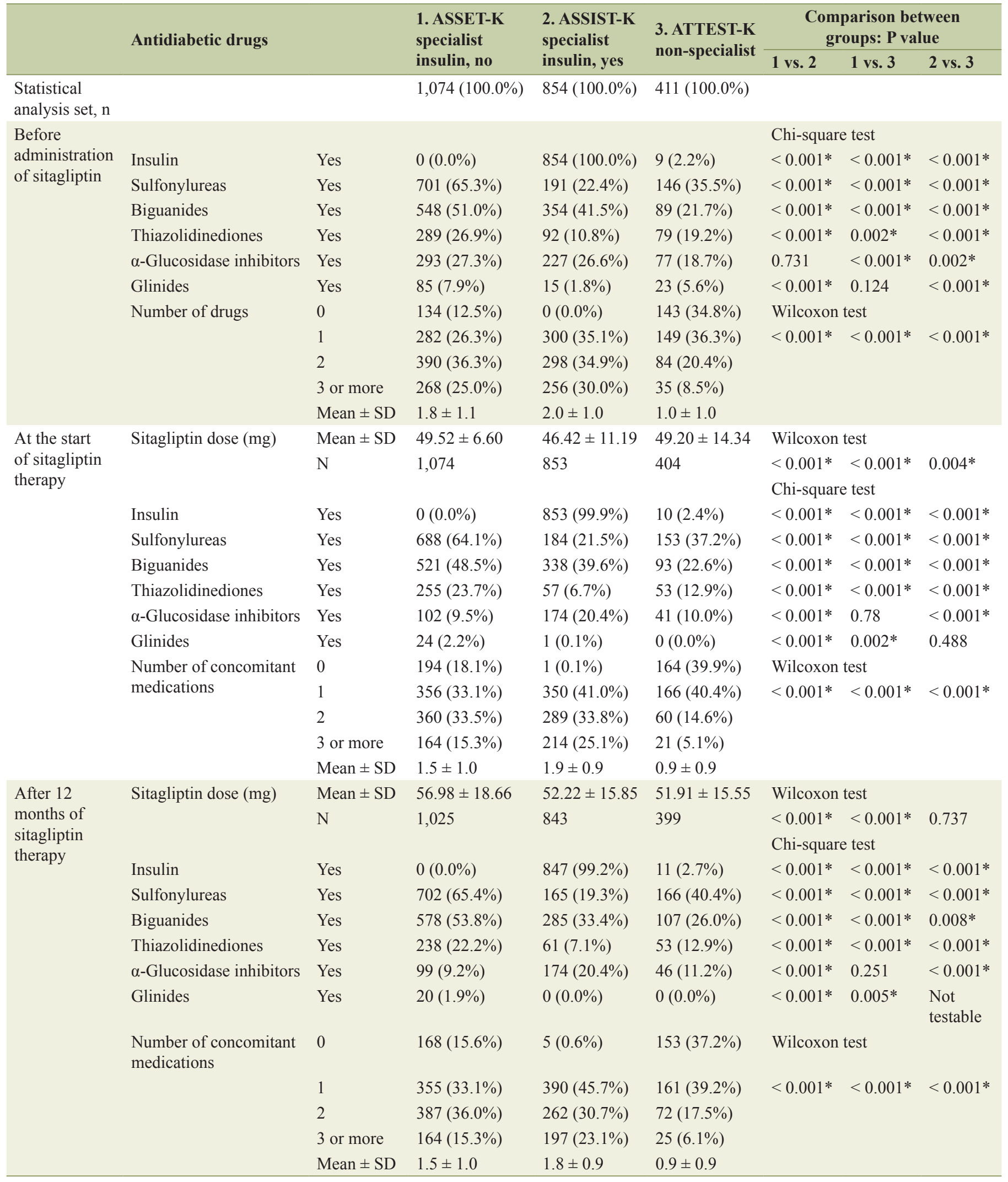

${ }^{*} \mathrm{P}<0.05$. SD: standard deviation. 

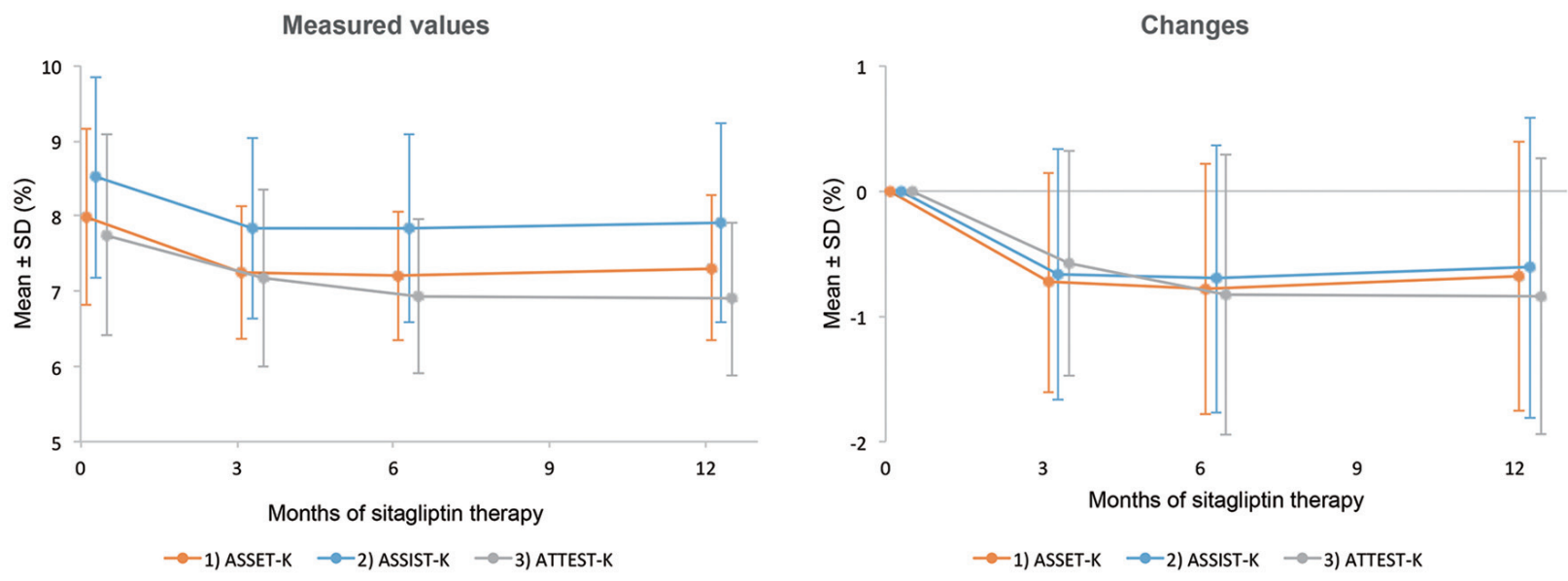

Figure 1. Changes in $\mathrm{HbA} 1 \mathrm{c}$. There was a significant decrease in $\mathrm{HbA} 1 \mathrm{c}$ after 12 months of sitagliptin therapy in all three studies.
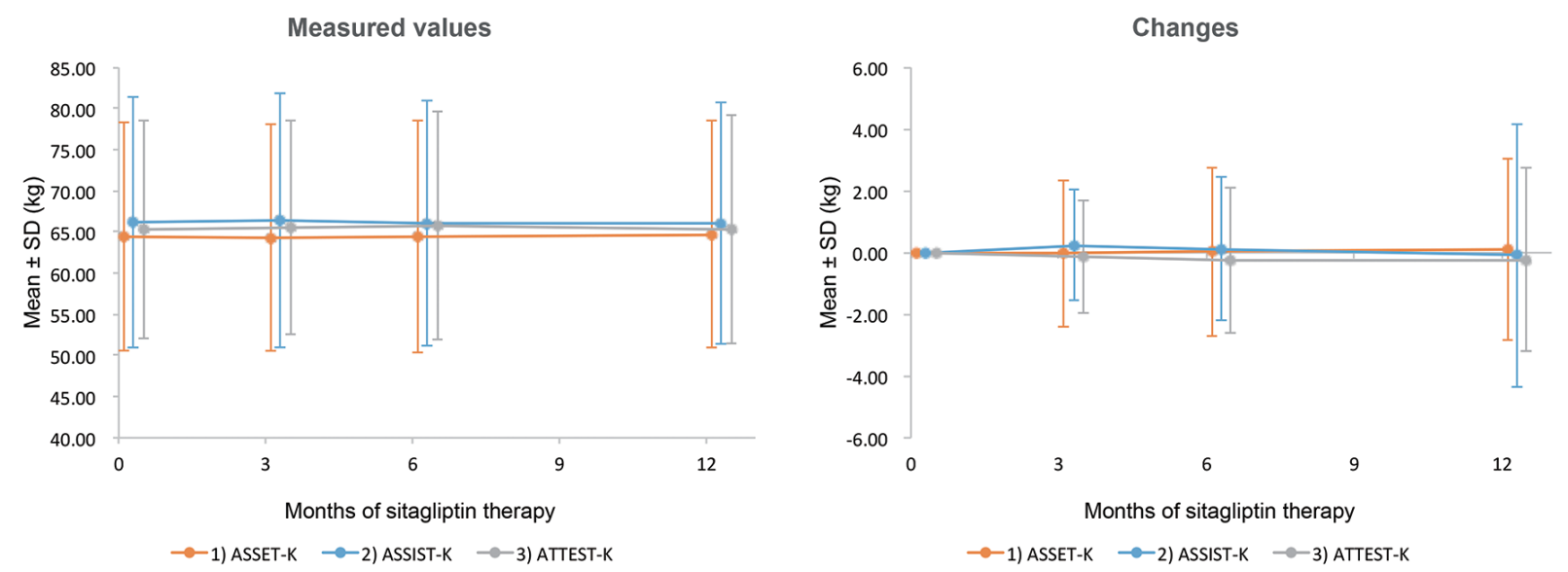

Figure 2. Changes in body weight. No significant change in body weight was seen after the start of sitagliptin therapy in all three studies.
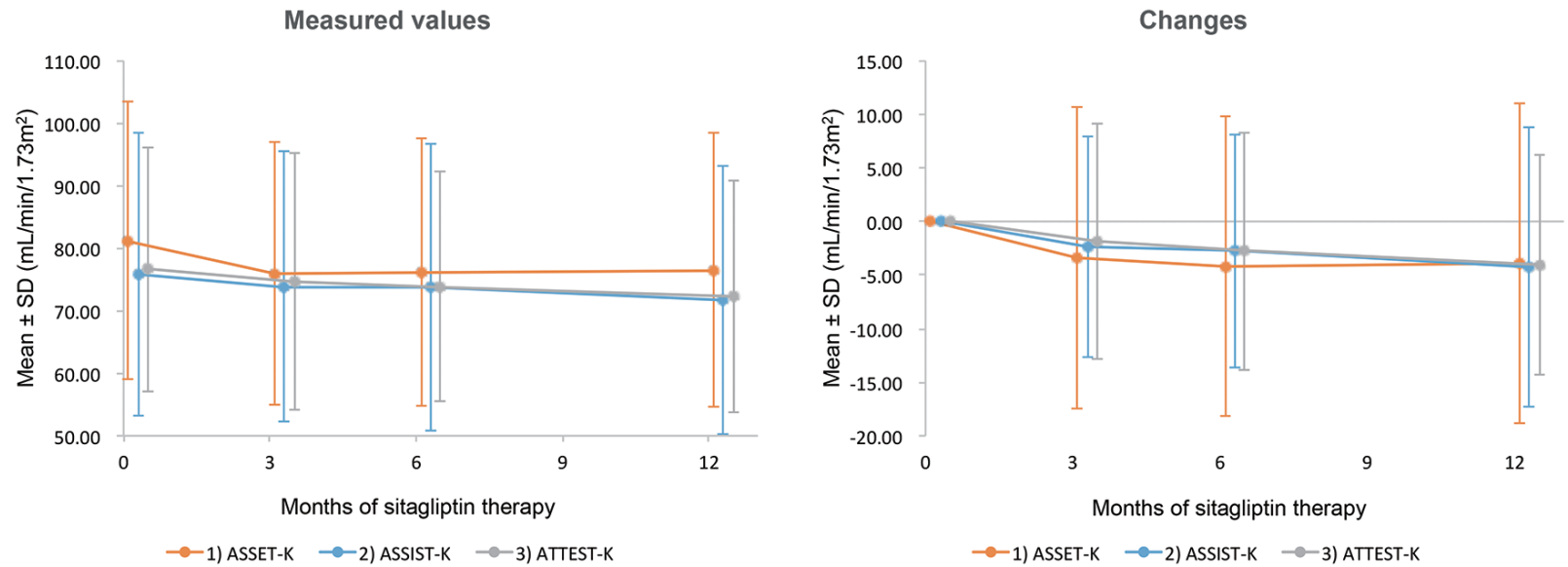

Figure 3. Changes in eGFR. A significant decrease in eGFR was noted after the start of sitagliptin therapy in all three studies. 


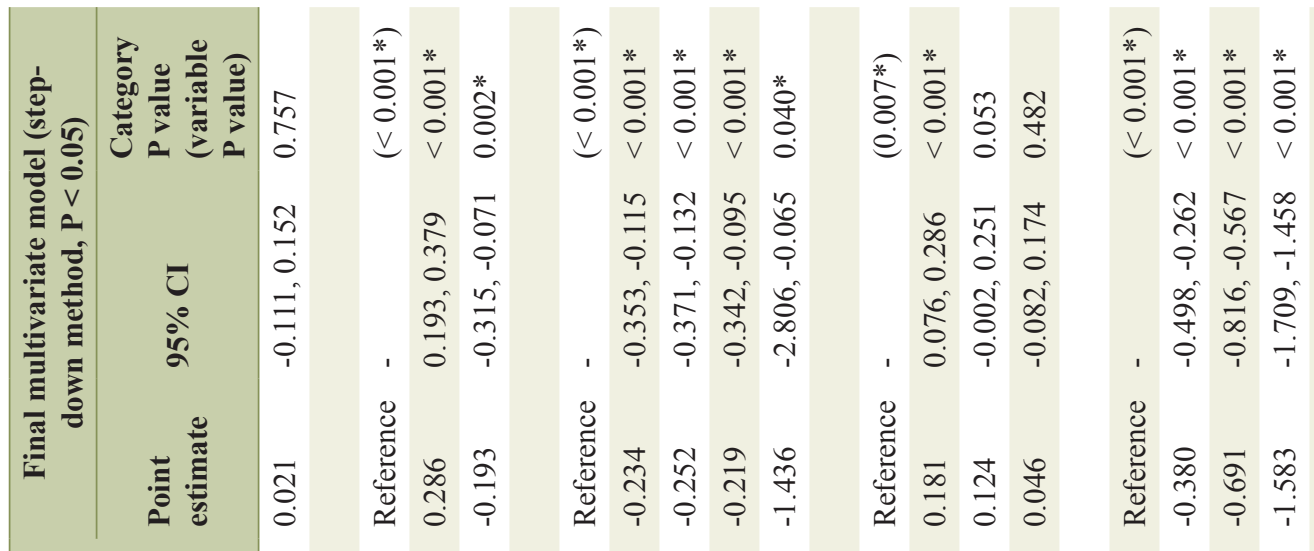

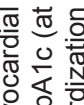

이웡

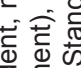

응 튼

需

元

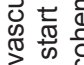

형 혼

可 훙

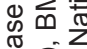

它

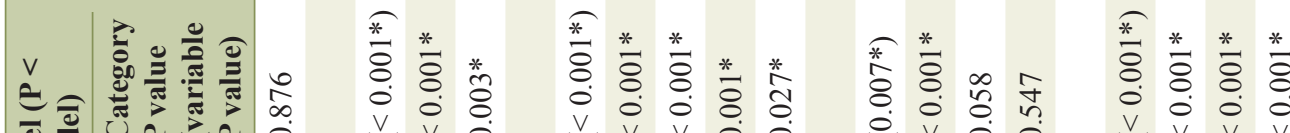

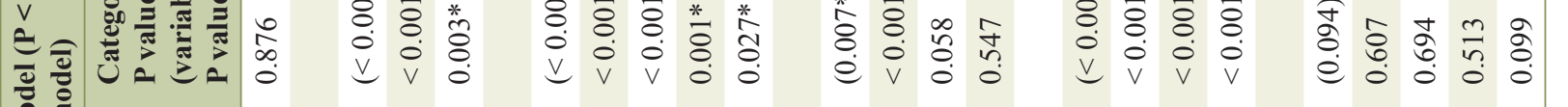

능

西

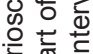

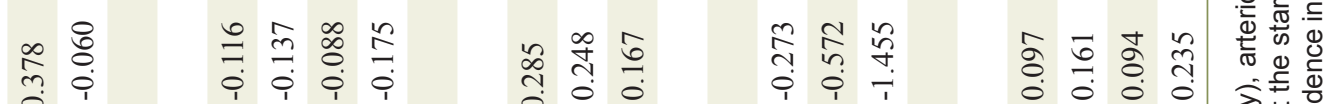

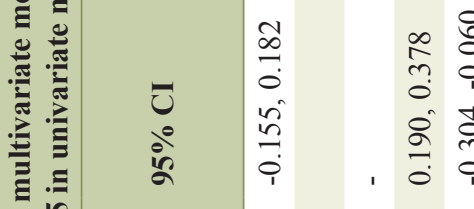

กิ 0

i 1

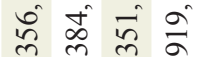

in $\begin{array}{lll}0 & 0 \\ 0 & 0 & 0 \\ 0 & 0 & 0 \\ 0 & 1 & 1\end{array}$

จิ สิ

$\begin{array}{llll}0 & 0 & 0 & 0 \\ 0 & 5 & 0 & 0 \\ 0 & 0 & 0 & 0\end{array}$

部要

, 1 i.

은 흠

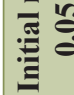

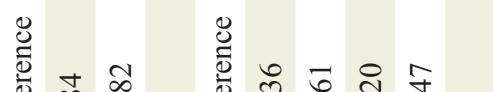

言产

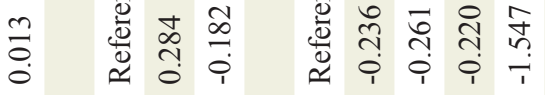

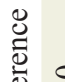

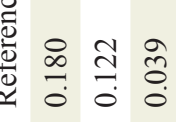

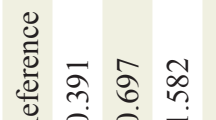

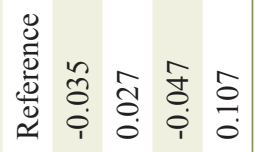

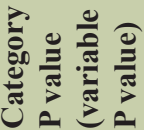

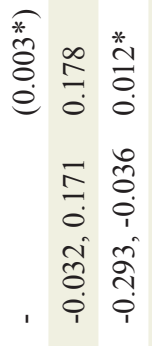

䍃

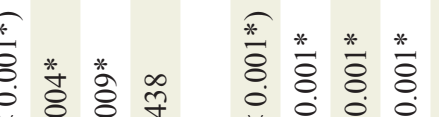

*

$\therefore$ 중흐

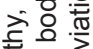

बi

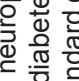

तें

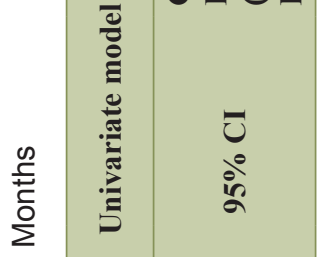

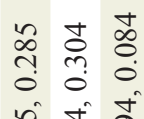

ชิ

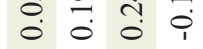

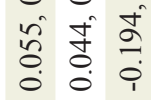

i

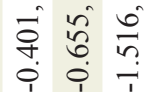

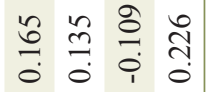

응.응

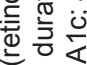

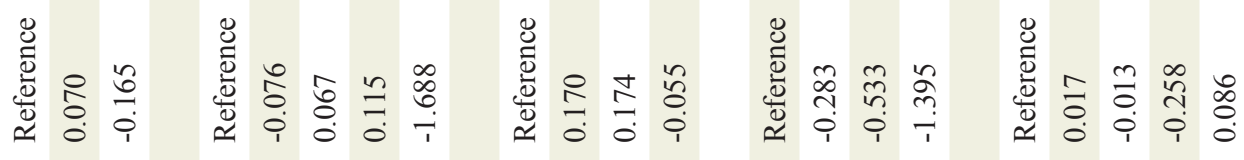

\&

足 $\frac{0}{5}$

సै

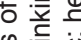

绍 등

变

䓂

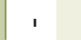

更

$\cong$ ㅇำ

भ oे

กิ $\infty \infty^{\infty} \overline{0}$

ㄷำ กิ

ฮี

일

을

용

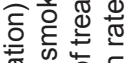

뜐 के व

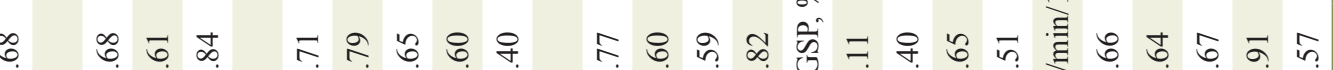

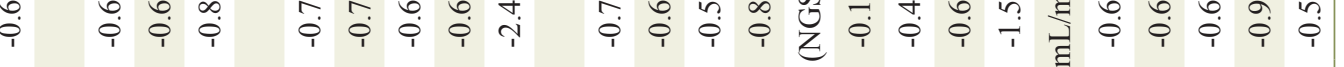

ले 点

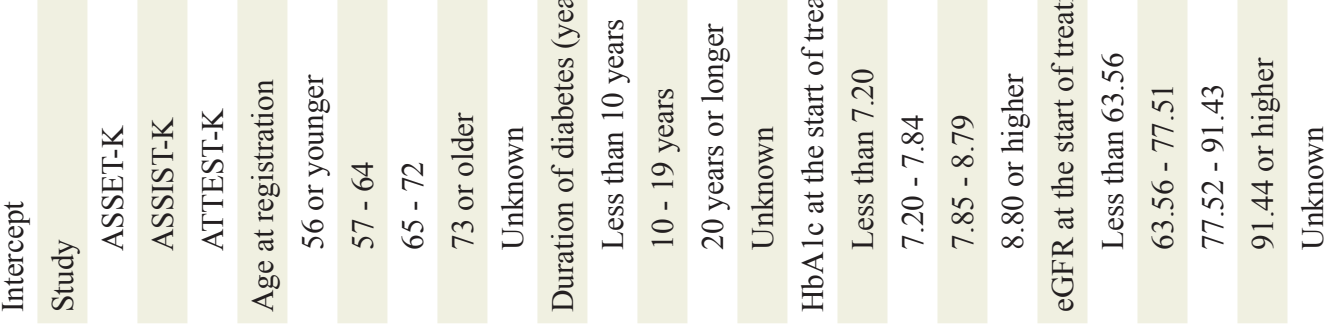

बi

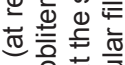

ब.

×.

is

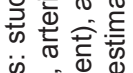

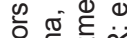

过

ᄂ

மீं

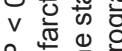




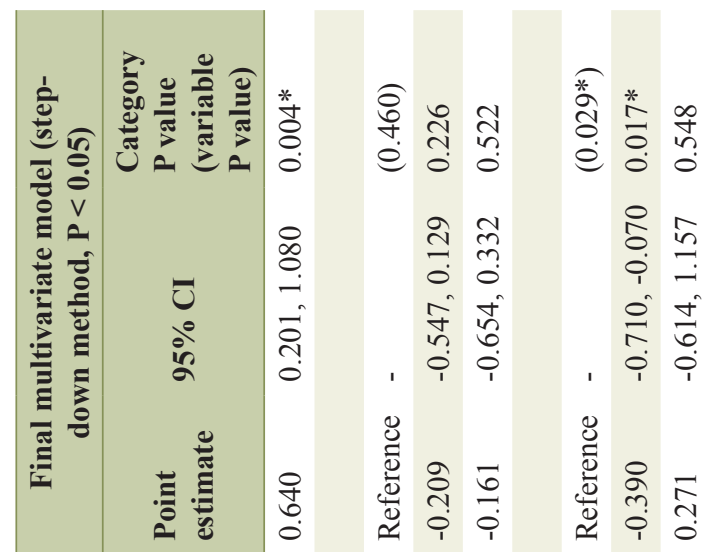

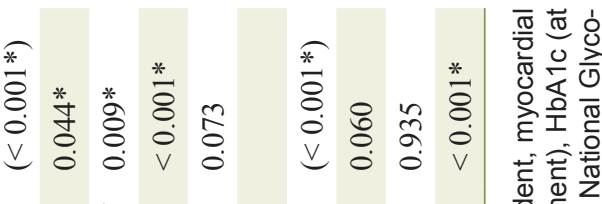

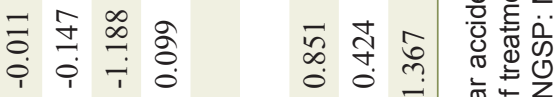

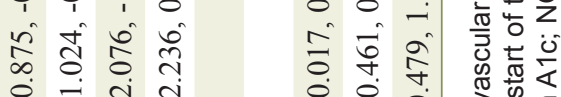

- 1 i 1 i 1 i

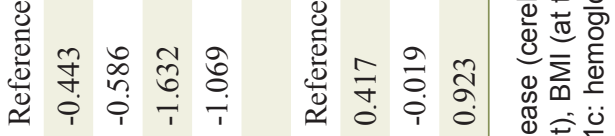

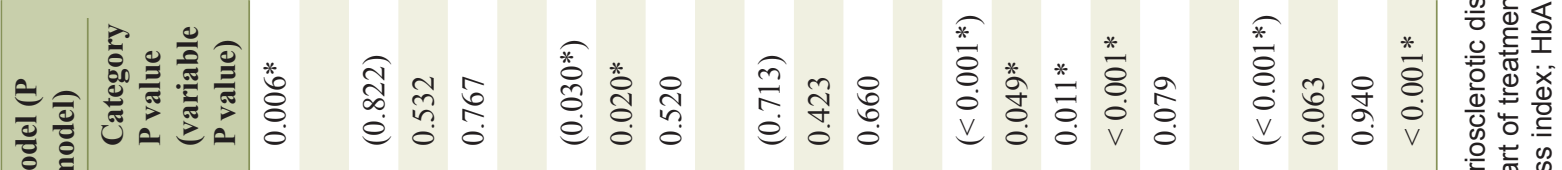

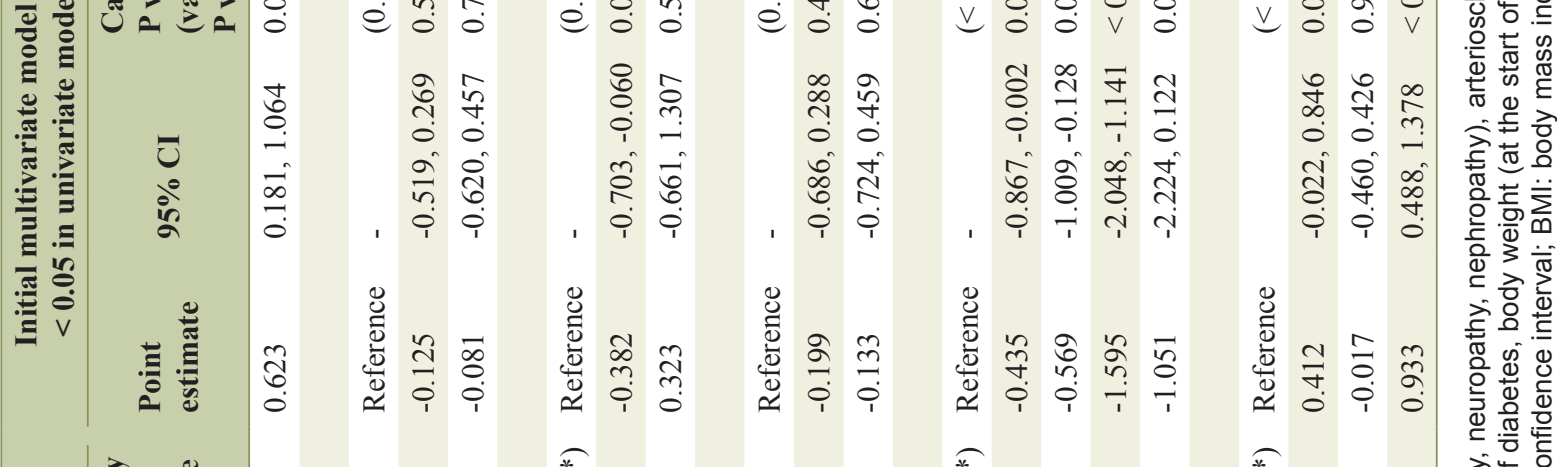

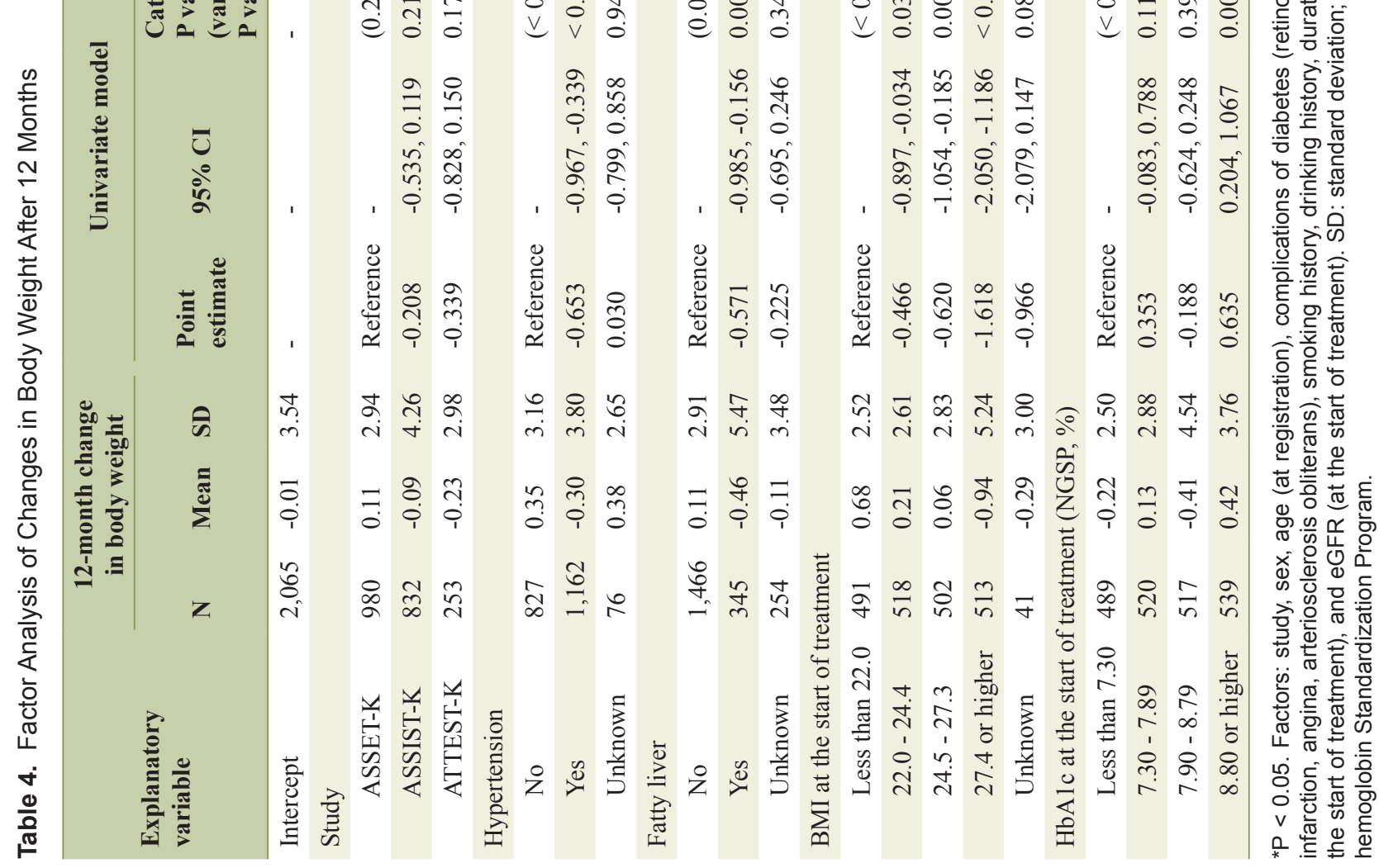

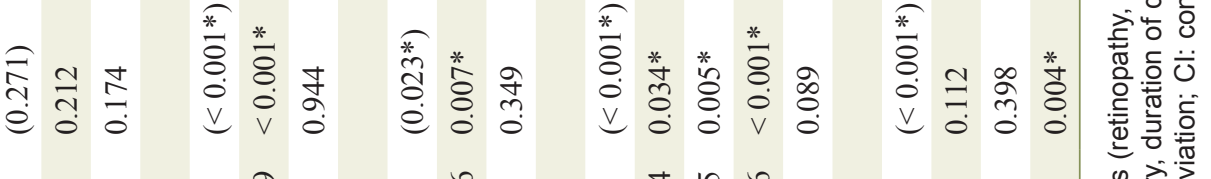

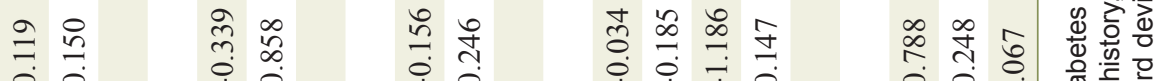

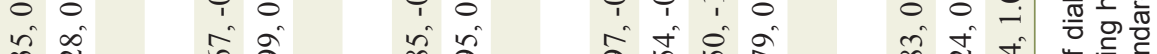

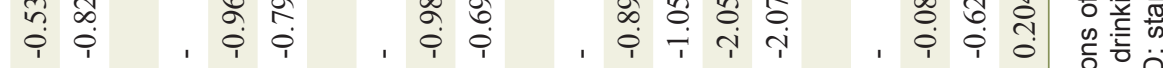

- 0 0 0 0

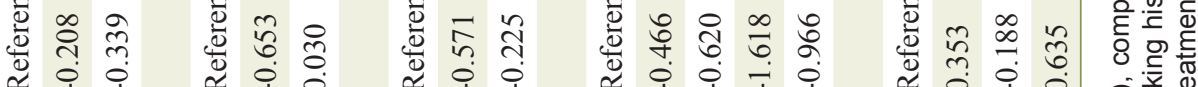




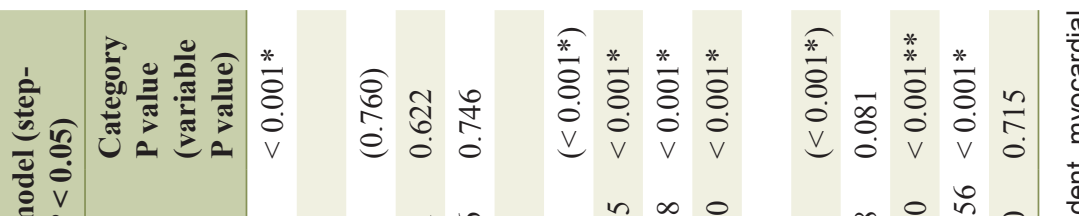

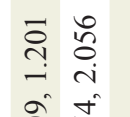

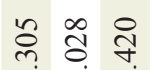

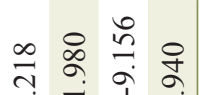

$\begin{array}{lll}1 & 1 & 1 \\ 1 & 0 & 0\end{array}$

त) i i

กี่

है

i $i$

ले भे

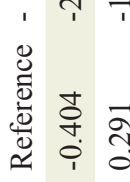

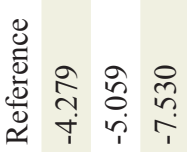

苞

言

1.5

爱言言言言高

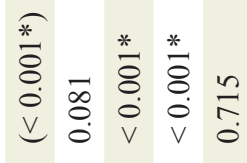

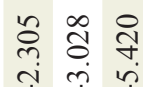

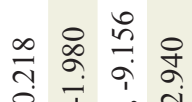

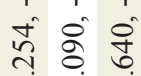

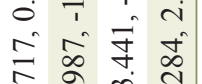

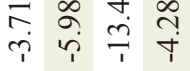

तु

苗

שू

要孛

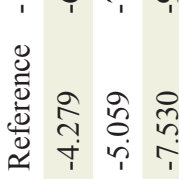

đ

志产

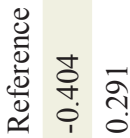

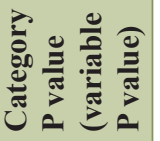

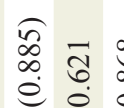

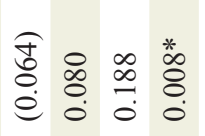

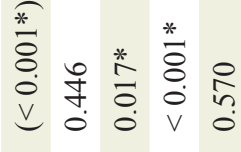

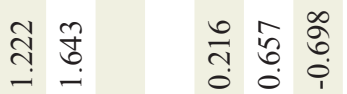

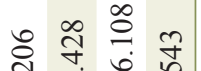

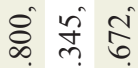

बें

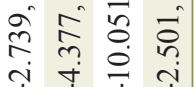

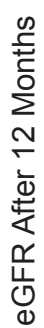

㝴告

- $\vec{i}$ के

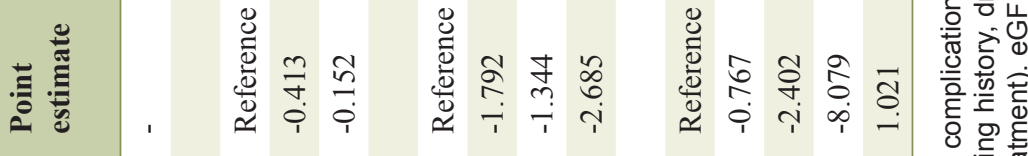

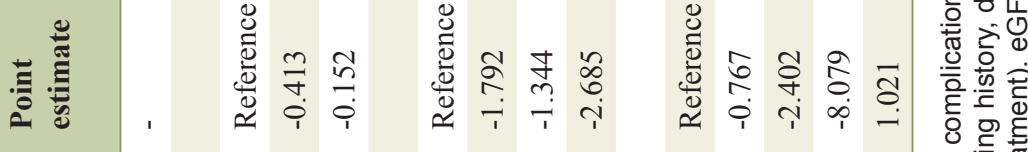

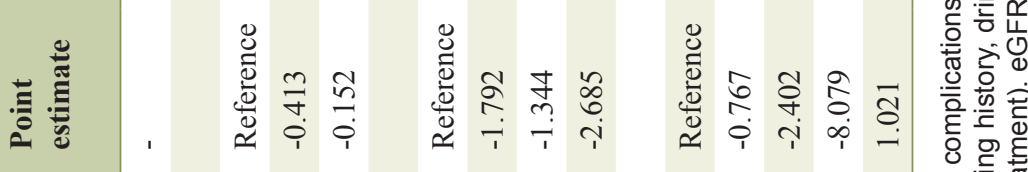

중요

잉 幽

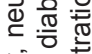

त्रे

政

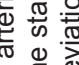

至

응 등

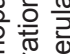

응 응

중ㅎㅇ

$\frac{0}{\pi}$

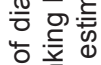

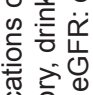

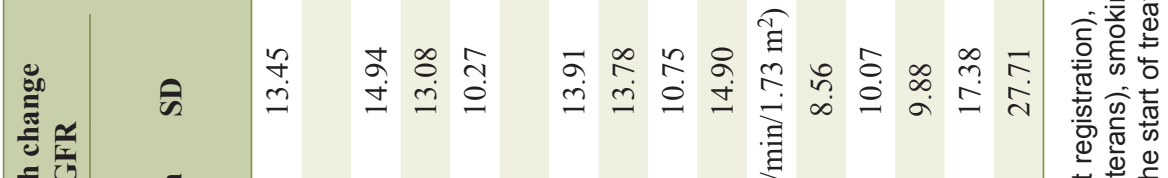

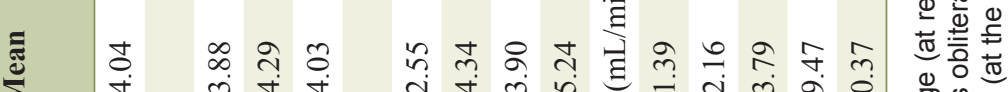

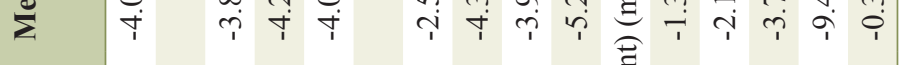

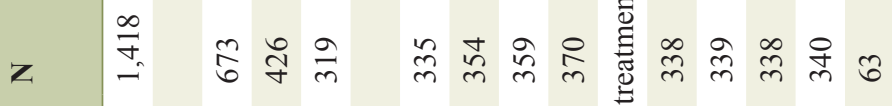

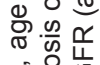

O

$\frac{\infty}{\infty}$

i่

is

$\frac{\sqrt{\frac{\pi}{4}}}{\frac{1}{2}}$

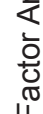

in

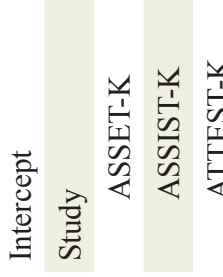

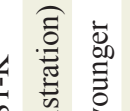

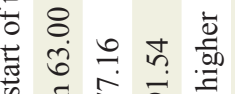

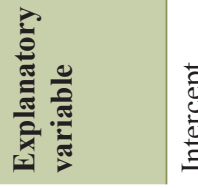

$\frac{\bar{t}}{0}$

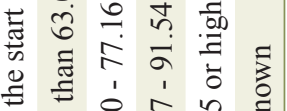

空离

ํำ

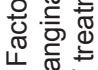

एᄂ.

웅흔듄

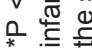


Multivariate analysis showed that the study, age at registration, duration of diabetes, and baseline $\mathrm{HbAlc}$ were the four factors with a significant influence on the change in HbA1c. The greatest reduction of $\mathrm{HbAlc}$ was seen in the ATTEST-K study, followed by ASSIST-K and ASSET-K in that order. HbAlc tended to decrease more in the older patients ( $\geq 57$ years old). With respect to the duration of diabetes, $\mathrm{HbAlc}$ showed a smaller decrease in patients with a long disease duration $(\geq$ 10 years). HbA1c showed a greater decrease in patients with a higher HbA1c at the start of treatment.

Table 4 displays the results of factor analysis of the changes in BW at 12 months. The factors with a significant influence according to univariate analysis were the presence of complications (hypertension/fatty liver), baseline BMI, and baseline $\mathrm{HbA1c}$. Multivariate analysis confirmed that hypertension, baseline BMI, and baseline HbA1c were the three factors with a significant influence on the change in BW, while the study had no significant impact. With respect to hypertension, patients without hypertension tended to gain weight, whereas patients with it tended to lose weight. BW tended to decrease in patients with a higher baseline BMI, while BW tended to increase when baseline $\mathrm{HbA1c}$ was $\geq 8.80$.

Table 5 lists the results of factor analysis of the changes in eGFR at 12 months. Factors showing a significant influence on the change in eGFR by univariate analysis were the age at registration and the baseline eGFR. Multivariate analysis confirmed that the age at registration and the baseline eGFR were factors with a significant impact, while the study had no significant effect. It was found that eGFR tended to decrease in older patients and patients with a higher baseline eGFR.

\section{Discussion}

In the present analysis, data from two previous studies of T2DM patients treated with sitagliptin by diabetologists (ASSET-K and ASSIST-K) were combined with data from a study of patients treated by non-diabetologists (ATTEST-K), and factor analysis of the changes in HbA1c, BW, and eGFR after 12 months of sitagliptin therapy was performed.

Patients in ASSIST-K (diabetologists/with insulin) were characterized by having more complications (complications of diabetes, arteriosclerotic disease, and other complications), a longer duration of diabetes, higher BW and BMI, higher baseline HbA1c, and lower baseline eGFR compared with patients in ASSET-K (diabetologists/without insulin). On the other hand, patients in ATTEST-K (non-diabetologists) were older and had fewer diabetic complications (retinopathy, neuropathy, and nephropathy), more non-diabetic complications (hypertension, dyslipidemia, and fatty liver), a shorter duration of diabetes, higher BMI, lower baseline HbA1c, and lower baseline eGFR compared with the ASSET-K patients. These results appeared to reflect differences between patients with or without insulin therapy and those treated by diabetologists or non-diabetologists.

The mean dose of sitagliptin was lower in ASSIST-K compared with ASSET-K both at the start of treatment (46.42 mg vs. $49.52 \mathrm{mg}$ ) and after 12 months of treatment $(52.22 \mathrm{mg}$ vs. $56.98 \mathrm{mg}$ ), and this appeared to reflect differences in the dosage of sitagliptin for patients with or without concomitant insulin therapy. The starting dose of sitagliptin was almost comparable in ATTEST-K and ASSET-K (49.20 mg vs. $49.52 \mathrm{mg}$ ), but the mean dose differed by about $5 \mathrm{mg}$ at 12 months (51.91 $\mathrm{mg}$ vs. $56.98 \mathrm{mg}$ ). Because the baseline HbA1c was relatively low in ATTEST-K compared with ASSET-K, dose escalation of sitagliptin might not have been necessary.

In both ASSIST-K and ATTEST-K, fewer antidiabetic agents (other than insulin) were administered before the start of sitagliptin therapy than in ASSET-K, reflecting differences such as the presence or absence of insulin treatment and other characteristics of the study populations (complications, duration of diabetes, etc.). After initiation of sitagliptin therapy, administration of TZDs, $\alpha$-GIs, and glinides decreased in all three studies. Between the start of sitagliptin therapy and 12 months, use of BGs increased in ASSET-K and ATTEST-K (48.5\% vs. $53.8 \%$ in ASSET-K and $22.6 \%$ vs. $26.0 \%$ in ATTEST-K), whereas it decreased (39.6\% vs. $33.4 \%$ ) in ASSIST-K, probably reflecting the presence or absence of insulin therapy in the study populations.

A significant decrease in HbA1c was observed after 12 months of sitagliptin therapy in all three studies. This suggested that sitagliptin is effective for reducing $\mathrm{HbAlc}$ irrespective of differences in insulin treatment and the level of specialist care (diabetologists/non-diabetologists). However, factor analysis of the changes in $\mathrm{HbA} 1 \mathrm{c}$ at 12 months showed significant inter-study differences. The decrease in HbAlc was smaller in ASSIST-K (diabetologists/with insulin) compared with ASSET-K (diabetologists/without insulin), suggesting that $\mathrm{HbA1c}$ shows less improvement in patients on insulin therapy than in patients without insulin after addition of sitagliptin. Also, the reduction of HbAlc was greater in ATTEST$\mathrm{K}$ (non-diabetologists) than ASSET-K (diabetologists/without insulin). One reason for this difference might be that there was little change in the percentage of patients using SUs from before initiation of sitagliptin therapy to 12 months in ASSET$\mathrm{K}$ (from $65.3 \%$ to $65.4 \%$ ), whereas use of SUs increased in ATTEST-K (from $35.5 \%$ to $40.4 \%$ ). Other factors that were associated with less improvement in $\mathrm{HbA} 1 \mathrm{c}$ were a younger age ( $<57$ years), a longer duration of diabetes ( $\geq 10$ years), and a low baseline $\mathrm{HbA1c}$.

There was no significant change in BW in any of the studies, a finding in agreement with previous reports [5, 6]. Factor analysis of the changes in BW at 12 months suggested that factors possibly related to weight gain were absence of hypertension, low baseline BMI, and high baseline HbA1c ( $\geq 8.80)$.

There was a significant decrease in eGFR over time in all three studies. All of the studies showed results consistent with the reported increase in serum creatinine after initiation of sitagliptin therapy in ASSET-K [13]. Factor analysis of the changes in eGFR over 12 months suggested that an older age at registration and high baseline GFR were related to the decline in eGFR.

We acknowledge that the three studies included in the present analysis were not necessarily homogenous and were conducted on an observational basis. This point needs to be taken into account in the interpretation of our findings. 


\section{Conclusion}

The present analysis employed data from the ASSET-K study (diabetologists/without insulin), ASSIST-K study (diabetologists/with insulin), and ATTEST-K study (non-diabetologists). Although there were differences in patient characteristics, treatment (such as the presence/absence of insulin therapy), and the level of specialist care (diabetologist/non-diabetologist) among the studies, consistent reduction of $\mathrm{HbAlc}$ by sitagliptin was confirmed in all three studies. Reduction of $\mathrm{HbAlc}$ by sitagliptin therapy was more likely in older patients with a shorter duration of diabetes and a higher baseline $\mathrm{HbAlc}$.

\section{Competing Interest}

The authors declare that there are no competing interests.

\section{Grant Support}

This research was supported by funds from the Japan Kidney Foundation and the Waksman Foundation of Japan.

\section{References}

1. Scheen AJ. A review of gliptins for 2014. Expert Opin Pharmacother. 2015;16(1):43-62.

2. Aroda VR, Henry RR, Han J, Huang W, DeYoung MB, Darsow T, Hoogwerf BJ. Efficacy of GLP-1 receptor agonists and DPP-4 inhibitors: meta-analysis and systematic review. Clin Ther. 2012;34(6):1247-1258 e1222.

3. Craddy P, Palin HJ, Johnson KI. Comparative effectiveness of dipeptidylpeptidase- 4 inhibitors in type 2 diabetes: a systematic review and mixed treatment comparison. Diabetes Ther. 2014;5(1):1-41.

4. Scheen AJ. Safety of dipeptidyl peptidase-4 inhibitors for treating type 2 diabetes. Expert Opin Drug Saf. 2015;14(4):505-524.

5. Plosker GL. Sitagliptin: a review of its use in patients with type 2 diabetes mellitus. Drugs. 2014;74(2):223242.
6. Lee M, Rhee MK. Sitagliptin for Type 2 diabetes: a 2015 update. Expert Rev Cardiovasc Ther. 2015;13(6):597610.

7. Maeda H, Kubota A, Tanaka Y, Terauchi Y, Matsuba I. The safety, efficacy and predictors for $\mathrm{HbA} 1 \mathrm{c}$ reduction of sitagliptin in the treatment of Japanese type 2 diabetes. Diabetes Res Clin Pract. 2012;95(1):e20-22.

8. Kubota A, Maeda H, Kanamori A, Matoba K, Jin Y, Minagawa $\mathrm{F}$, Obana $\mathrm{M}$, et al. Pleiotropic effects of sitagliptin in the treatment of type 2 diabetes mellitus patients. J Clin Med Res. 2012;4(5):309-313.

9. Kubota A, Maeda H, Kanamori A, Matoba K, Jin Y, Minagawa F, Obana M, et al. Efficacy and safety of sitagliptin monotherapy and combination therapy in Japanese type 2 diabetes patients. J Diabetes Investig. 2012;3(6):503-509.

10. Kanamori A, Matsuba I. Factors associated with reduced efficacy of sitagliptin therapy: analysis of 93 patients with type 2 diabetes treated for 1.5 years or longer. J Clin Med Res. 2013;5(3):217-221.

11. Maeda H, Kubota A, Kanamori A, Tanaka Y, Terauchi Y, Matsuba I. Long-term efficacy and safety of sitagliptin in the treatment of Japanese Type 2 diabetes (ASSET$\mathrm{K} 1)$ to a target of $\mathrm{HbAlc}<7 \%$. J Endocrinol Invest. 2013;36(8):568-573.

12. Umezawa S, Kubota A, Maeda H, Kanamori A, Matoba $\mathrm{K}$, Jin Y, Minagawa F, et al. Two-year assessment of the efficacy and safety of sitagliptin in elderly patients with type 2 diabetes: Post hoc analysis of the ASSET-K study. BMC Endocr Disord. 2015;15:34.

13. Maeda H, Kubota A, Kanamori A, Tanaka Y, Terauchi Y, Matsuba I. Effects of sitagliptin on the serum creatinine in Japanese type 2 diabetes. Diabetes Res Clin Pract. 2015;108(3):e42-45.

14. Takai M, Ishikawa M, Maeda H, Kanamori A, Kubota A, Amemiya H, Iizuka T, et al. Safety and efficacy of adding sitagliptin to insulin in patients with type 2 diabetes: the ASSIST-K study. Diabetes Res Clin Pract. 2014;103(3): e30-33.

15. Ishikawa M, Takai M, Maeda H, Kanamori A, Kubota A, Amemiya H, Iizuka T, et al. Factors Predicting Therapeutic Efficacy of Combination Treatment With Sitagliptin and Insulin in Type 2 Diabetic Patients: The ASSIST-K Study. J Clin Med Res. 2015;7(8):607-612. 